\title{
INFORMATION AND KNOWLEDGE OF PUBLIC SECTOR DECISION MAKERS: EXPERIMENTAL RESEARCH IN THE CONTEXT OF A LOCAL GOVERNMENT HOSPITAL IN INDONESIA
}

\author{
Icuk Rangga Bawono \\ Faculty of Economics and Business \\ Universitas Jenderal Soedirman \\ (cukycutes@yahoo.com) \\ Abdul Halim \\ Faculty of Economics and Business \\ Universitas Gadjah Mada \\ (ahali58@ugm.ac.id)

\section{Beverley R. Lord} \\ Department of Accounting and Information Systems \\ University of Canterbury \\ (B.Lord@afis.canterbury.ac.nz)
}

\begin{abstract}
This research aimed to test the previous result of experimental research on decision making by Dilla and Steinbart (2005), and to internalize the result in the context of a local government hospital in Indonesia. The subjects in this experiment were 80 members of the House of Representatives in the Cilacap, Brebes and Purbalingga regions in Indonesia. They were asked to evaluate the performance of a fictitious local government hospital and decide whether or not to increase its budget allocation for the coming year. Half of the subjects were given instruction in the performance measures applicable to hospitals; the other half proceeded straight to the experimental task. The first group were labelled "knowledgeable users"; the latter group were classified as "unknowledgeable".

The results of this experiment using real decision makers showed that the knowledgeable group tended to use the unique information given to them to measure performance and make budget allocation plans, whereas the unknowledgeable group used common measures. These results are consistent with Lipe and Salterio (2000), Dilla and Steinbart (2005) and Bawono et al. (2012), indicating that students may be reliable surrogates for real decision makers.
\end{abstract}

Keywords: accountability, public sector, performance measurement, budget allocation plan, knowledgeable and unknowledgeable, decision makers

\section{INTRODUCTION}

This research focused on which performance measures decision makers used in order to determine the success of public sector organizations in Indonesia. Most organizations, not only in the private sector but also in the non-profit and public sectors, have performance assessment mechanisms to assess whether the organization has been running on track or needs to improve its performance. Performance has traditionally been measured in financial terms, comparing the budget that has been set with actual realization. In recent years, private sector organizations have been developing and using more comprehensive performance measurement systems, incorporating both financial and non-financial measures.

One of these systems, using both financial and non-financial measures, is the Balanced 
Scorecard (BSC). To test whether users of the BSC understood the various measures and used them equally in evaluating performance, Lipe and Salterio (2000) designed an experiment in which MBA students evaluated the relative performance of two companies by examining their BSCs. Two of the measures for each perspective of each BSC were the same (called common measures); the other two measures for each perspective only appeared on one company's BSC and were specific (unique) to the strategy, product and market of that particular company. The other company had a different set of unique measures. When the participants evaluated which of the two companies had performed better, they only focused on the common measures, as comparisons were easier, even though the unique measures were indicating better performance for the other company.

Dilla and Steinbart (2005) wondered whether part of the reason for Lipe and Salterio's findings was that the student participants had no prior experience with the BSC, that is, they were "unknowledgeable". Dilla and Steinbart repeated the experiment using accounting and information systems students who had studied and tried designing BSCs. They found that these participants did consider the unique measures as well as the common measures, but they still put more weight on the common measures in evaluating the performance of each company.

Royal et al. (2013) explained leadership in public sector organizations as requiring a highlevel understanding of power. Public sector organizations invest more in human resources rather than in profits. Hence, this sector offers a major source of theoretical and empirical understanding of the role of the formation of knowledge and organizational learning. Learning competencies, in particular, are more imperative in the non-profit environment. For example, the significant stakeholders' management of public sector organizations makes them more vulnerable to conflicts between the organization and the staff as a result of this ambiguity. Barriers to organizational learning are important because such barriers provide a detailed classification of the competencies required for learning. The process to overcome such barriers to learning needs to be investigated, especially in public sector organizations. Barriers include; a lack of trust, the lack of employee skills to implement innovations and also the lack of ability by the management to institute learning experiences impacts on the learning organization, which requires extraordinary dexterity to make it work.

In public sector organizations, where budgets are discretionary and allocated by the government, performance measurement may be used to evaluate whether the budgeted allocation of funds for the next year will be revised upwards, remain the same or even be cut. This performance measurement is mandatory in Indonesia (Government of the Republic of Indonesia Regulation No. 71/2010). Measurements will be carried out carefully by the legislature (such as the local regional representatives) as the stakeholders who represent the people. Yudono (2002) claimed that parliament can only play its role properly if the leaders and members have the necessary qualifications, levels of education and experience in politics and government to understand and carry out their duties and responsibilities.

Bawono et al. (2012) focused on the role of information and knowledge in the public sector decision making process in the context of general hospitals. The experiments were carried out using students as surrogates for the governments' representatives on the hospital boards. One group of participants was first given instruction in various performance measures unique to the evaluation of hospitals. Both the group given the information and the other group were then asked to evaluate the performance of a fictitious hospital and decide whether to increase the budget for the next year or leave it the same. The group that was given the extra instruction tended to use the information unique to hospitals as a basis for their decisions about the budget allocation for the next year, while the group that was not given instruction tended to use only the general information as a basis for making decisions, even when they were provided with both the common and unique measures. 
These three studies reviewed above all used students as surrogates for the decision makers. Bawono et al. (2012) raised the question of whether real decision makers would make similar decisions, as they would have different educational backgrounds and more experience than young students, many of whom would not have worked full time. Therefore this study repeats the experiment carried out in Bawono et al. (2012), but using a sample of members of the local government, participants who would have to make decisions about budget allocations in real life.

\section{THEORETICAL FRAMEWORK AND HYPOTHESES}

Libby (1993) suggested a simple model for the acquisition of knowledge and skills which determined the performance capabilities and instructions, experience and ability to determine the acquisition of knowledge, therefore known as the 'Knowledge acquisition theory'. The most important implication of the model was a detailed understanding of the process of the acquisition of knowledge that was required before the practical implications of the study were clear.

Furthermore, the quantity and quality of training and the feedback were varied. Good practice and feedback should be considered as part of the "experience." In this study, researchers focused on the acquisition of knowledge through various combinations of instructions which were then considered part of the "experience". Performance evaluations of public sector organizations in Indonesia commonly compare the budget with the actual performance. However, this traditional view of performance only considers the use of financial inputs. It does not take into consideration outputs and outcomes, and whether inputs have been used effectively as well as efficiently and economically (Hyndman and McGeough, 2008). Effectiveness pays attention to the relationship between outputs or outcomes and organizational goals. For example, if the goal of a public sector organization is to reduce infant mortality by 10 percent within a year, measurements of the effectiveness of performance will compare the actual results with that objective. Output and outcome measures are likely to be unique to each organization, and non-financial.

Performance measurement and budget allocation planning that is used in many public sector organizations emphasizes the common measurement rather than considering the unique measurement. Common measurement is a measurement commonly used by all units/work units, while the unique measurements are measurements used by a unit/specific work unit. In contrast to the emerging paradigm, it emphasizes both measurements as a single unified integrated process.

Budget allocation planning is one part of public sector budgeting. Budget allocation plans delineate the level of monetary resources that will be used in a program or by an organizational unit in order to carry out their plans and achieve their outcomes. Therefore the criteria that decision makers use in their resource allocation determination are really important. Decision makers use performance information to determine whether the allocation of the budget for the coming year will be raised, lowered or remain the same.

Yudono (2002) claimed that members of the local regional representatives would be able to exercise their rights properly, carry out their tasks and duties effectively and play their part in decision making if each member had sufficient knowledge of the technical concepts of governance and public policy. Knowledge is required for supervising local government finances; in particular, knowledge about budgeting. Most previous studies have found that the regional members' knowledge about the budget affects, or has a relationship with, the regions' financial supervision (Sopanah, 2003; Werimon, 2003; Coryanata, 2007; Winarna and Murni, 2007; Basri, 2007). ${ }^{1}$

There are differences in the ability of members to read and analyse performance reports. Some decision makers in government have a lot of experience and understanding of performance reports, while others do not. Research into other accounting fields, such as auditing, has found 
that more knowledge results in better decision making (Bonner, 1990). Knowledge of different types of performance measures can be provided through training, courses, books, seminars and scientific journals. In this research, knowledge was provided to some decision makers to see if that made them more aware of important parts of the performance report in making their decisions. This test is stated in the following hypotheses:

$\mathrm{H}_{1}$ : Decision makers who are knowledgeable about performance measurement will make different appraisals of performance to those of unknowledgeable decision makers.

$\mathrm{H}_{2}$ : Decision makers who are knowledgeable about performance measurement will make different budget allocation decisions than the unknowledgeable decision makers.

Performance reports produced by government organizations typically contain both the common and unique performance measures of a unit. For example, from hospitals, the house receives both financial and non-financial performance reports, each containing common and unique measures. Decision makers pay attention to these performance measures and then conclude whether a hospital's performance is good or bad. This research concerns how decision makers use both of these common and unique performance measures.

Dilla and Steinbart (2005) hypothesized that decision makers, who understand the theory as well as the structure of the BSC, would be more likely to use both common and unique measures when comparing and evaluating performance. However, their results showed that even though unique measures were considered, more weight was placed on the common measures. Other studies (for example, Libby et al., 2004; Gagne et al., 2006) have found that decision makers who have had experience with performance reports, and their common and unique performance measures, use both types of measures, but they give more emphasis to the unique measures than the common ones. To further test these conflicting findings, the following hypotheses were developed:
H3: Decision makers who have access to both common and unique information will make different appraisals of performance than the decision makers who have access to only the common information.

H4: Decision makers who have access to both common and unique information will make different budget allocation decisions than decision makers who have access to only the common information.

\section{RESEARCH METHOD}

Public sector accounting research uses an experimental method with its emphasis on strengthening internal validity. This does not mean that external validity is not of concern, as it is. Nahartyo (2013) argued that research focusing on the experimental method could still be said to be rare in the context of Indonesia. Moreover, research that has focused on the field of performance measurement and budget allocation planning, in the realm of the public sector by using the experimental method is still very rare within the Indonesian context.

This study used a 2 x 2 factorial design with one factor for the type of information (common or unique) and one factor for knowledge (knowledge is given or knowledge is not given). Within-subject design compared the effects of different treatments on different subjects. This method was selected because it was able to test the interaction effect of independent variables on the dependent variable and it avoided a demand effect, in which the subjects know the direction of the given treatment (Campbell and Stanley, 1966; Nasution and Supriyadi, 2007).

The 80 subjects in the study were members of the Regional House of Representatives (abbreviated to DPRD in Indonesian) in the Central Java districts of Cilacap, Brebes and Purbalingga in Indonesia. These subjects would be making decisions related to performance measurements and budget allocation plans in their roles as members of the regional parliament. The subjects received a snack, lunch and a book as compensation for their participation. 
The experiment used the same procedure and instruments as in Bawono et al. (2012), as summarized here. The subjects were divided into four different groups. Groups A1 and A2 were given brief training on common and unique performance measurement for an hour. During the short course, the subjects were given instruction in performance measurement, the budget allocation process, how to read and interpret the financial statements of public hospitals, and the importance of using some measurements that are unique to the assessment of performance. After a few minutes to absorb the training, these "knowledgeable" groups proceeded to the experiment. Groups B1 and B2, the "unknowledgeable" groups did not receive any training.

In the experiment itself, participants were given budget reports for two fictitious regional public hospitals, either Hospital 1 or Hospital 2. Hospital 1's report comprised of its budget and actual figures for revenue and expenditure (five common types of information). Hospital 2's report comprised of the same two measures of common information as for Hospital 1, plus three measures of unique information, namely, performance ratios for the Bed Occupancy Rate (BOR), Length of Stay (LOS) and Bed Turn Over (BTO). Thus there were four groups of subjects, divided according to whether or not they had received the training (A or $\mathrm{B}$ ), and according to which hospital report they examined (1 or 2) (see Table 1).

Subjects from both group A and group B were asked to read and to review the information related to the performance of either Hospital 1 or Hospital 2, and then provide an assessment of the hospital's performance and propose a budget allocation for the coming year. Each hospital's performance was assessed on a scale from "Did not meet budget", through "Met budget", to "Above budget". Assessment of each hospital's performance was the basis for the decision to increase, maintain or decrease its budget for the next year. Subjects were given a maximum of 30 minutes to provide a decision on the hospital's budget allocation.

After the experiment, the subjects filled in a short questionnaire to check whether they understood the forms given to them and the experimental task, and to collect demographic data, namely, gender, education level and age. Table 2 shows that the treatment group (those given the training) and the control group (those without the training) were similar in respect to gender.

Table 2. Participants by Gender

\begin{tabular}{lccc}
\hline \multirow{2}{*}{ Gender } & \multicolumn{2}{c}{ Group } & \multirow{2}{*}{ Total } \\
\cline { 2 - 3 } & Treatment & Control & \\
\hline Male & 30 & 28 & 58 \\
Female & 10 & 12 & 22 \\
\hline Total & 40 & 40 & 80 \\
\hline
\end{tabular}

Table 3. Participants by Level of Education

\begin{tabular}{lccc}
\hline \multirow{2}{*}{ Gender } & \multicolumn{2}{c}{ Group } & \multirow{2}{*}{ Total } \\
\cline { 2 - 3 } & Treatment & Control & \\
\hline High School & 8 & 5 & 13 \\
Diploma & 10 & 12 & 22 \\
Undergraduate & 20 & 22 & 24 \\
Master & 2 & 1 & 3 \\
Total & 40 & 40 & 80 \\
\hline
\end{tabular}

Table 4. Participants by Age

\begin{tabular}{lccc}
\hline \multirow{2}{*}{ Gender } & \multicolumn{2}{c}{ Group } & \multirow{2}{*}{ Total } \\
\cline { 2 - 3 } & Treatment & Control & \\
\hline Under 30 & 4 & 3 & 7 \\
$31-45$ & 18 & 23 & 41 \\
$45-55$ & 12 & 10 & 22 \\
Over 55 & 6 & 4 & 10 \\
\hline Total & 40 & 40 & 80 \\
\hline
\end{tabular}

\section{RESULTS}

The first hypothesis (H1) was that the groups who received training in performance measurement (Groups A1 and A2) would differ from

Table 1. Experimental Groups

\begin{tabular}{lcc}
\hline & Knowledgeable & Unknowledgeable \\
\hline Common measures & Group A1 & Group B1 \\
Both common and unique measures & Group A2 & Group B2 \\
\hline
\end{tabular}


those who did not receive training when appraising performance. Results of a MANOVA (Multivariate) analysis showed statistical differences between the knowledgeable and unknowledgeable groups in their appraisal decisions. This was indicated by an F-value of 37.5, significant at $\mathrm{p}$ $<0.001$ (see Table 5).

Table 5. Knowledgeable versus Unknowledgeable

\begin{tabular}{lrcc}
\hline \multicolumn{1}{c}{ Dependent variable } & Mean Sq. & F & Sig \\
\hline Decision performance & 0.841 & 37.465 & .000 \\
The decision & 11.025 & 44.807 & .000 \\
\hline
\end{tabular}

In the second hypothesis (H2), the test compared the budget allocation decisions of the knowledgeable group and the unknowledgeable group. The reports showed that the financial targets had been met. However the non-financial measures were not achieved. From both of the hypotheses above ( $\mathrm{H} 1$ and $\mathrm{H} 2$ ), the group that had the training was more likely to make a decision to maintain the same budget allocation $(\mathrm{F}=$ 44.8, $\mathrm{p}<0.001$ - see Table 5).

The third hypothesis (H3) was tested by comparing the performance appraisal by the group that had both the common and unique information with the appraisal of the group that only had the common information. There was a statistically significant difference between the groups ( $F=38.9$, $p<0.001$ - see Table 6 ).

Table 6. Common versus Common and Unique Information

\begin{tabular}{lrcc}
\hline Dependent variable & Mean Sq. & F & Sig \\
\hline Decision performance & 0.740 & 38.858 & .000 \\
The decision & 9.025 & 35.174 & .000 \\
\hline
\end{tabular}

The test of the fourth hypothesis (H4) found that the group with both the common and unique information made better budget allocation decisions than the other group $(\mathrm{F}=35.2, \mathrm{p}<0.001$ - see Table 6).

\section{CONCLUSION AND DISCUSSION}

All of the hypotheses were supported. These results add to the literature on performance evaluation in a number of ways. Firstly, the tests of hypotheses 1 and 2 showed that providing training to decision makers will improve their understanding of performance measures and their decisions based on those measures. The unique measures provided for Hospital 2 in the experiment showed that although the budget had been met in financial terms, other non-financial targets had not been met. The "knowledgeable" group therefore correctly appraised the performance as not being good enough, and decided not to allocate more funds in the next budget. Even though group B2 had the unique measures, they did not understand their significance, and therefore made their decision based on the good performance indicated by the common measures, and thus allocated more money to the next year's budget.

Secondly, the tests of hypotheses 3 and 4 showed that the provision and use of unique and non-financial measures helped the decision makers in their appraisal of the performance and decisions based on that appraisal. Educators with an interest in the public sector could provide training and work alongside those in government-funded organizations, to help them to develop more informative and relevant targets and measures of their effectiveness in achieving the desired outputs and outcomes from the budget inputs allocated to them by local parliaments.

Some previous research used students as surrogates for real decision makers. Whether they were valid proxies has been questioned. However, this current study, which used real decision makers as the subjects of the experiment, had similar findings to earlier studies which used the students as surrogates. This lends more credibility to the results of the previous studies, as it seems that the students were reasonably good proxies for the decision makers they were representing. A suggestion for future research is the researcher could add to the analysis with an examination of how the correlation between the variables is maintained.

\section{REFERENCES}

Basri, M. Y. 2007. The Effect of Members of the House of Representative's Knowledge about Local Budgetary Methods, journal of State 
Administration, Vol. 9, No. 1, January 2007, pp. 29-39.

Bawono, I. R., Halim, A. and Lord, B. R. 2012. Public Sector Performance Measurement and Budget Allocation: An Indonesian Experiment, $6^{\text {th }}$ New Zealand Management Accounting Conference, Massey University, Palmerston North, New Zealand, 22-23 November.

Bonner, S. E. 1990. Experience Effect in Auditing: The Role of Task-Specific Knowledge. The Accounting Review, Vol. 65, pp. 72-92.

Campbell, D. T. and Stanley, J. C. 1966. Experimental and Quasi-experimental Designs for Research. Rand McNally: Chicago.

Coryanata, I. 2007. Accountability, Public Participation and Public Transparency Policy as Moderating Variables for Members of the House of Representative's Knowledge about budget and Local Financial Supervision], Article, $10^{\text {th }}$ National Accounting Symposium, Makassar, Indonesia, July 26-28.

Dilla, W. N. and Steinbart, P. J. 2005. Relative Weighting of Common and Unique Balanced Scorecard Measures by Knowledgeable Decision Makers. Behavioral Research in Accounting, Vol. 17, pp. 43-53.

Gagne, M., Holister, J. and Tully, G. J. 2006. Using the Balanced Scorecard: Both Common and Unique Measure Are Informative. Journal of Applied Business Research, Vol. 22, No. 1, pp. 147-160.

Hyndman, N. and McGeough, F. 2008. NPM and Performance Measurement: A Comparative Study of the Public Sectors in Ireland and the UK. Irish Accounting Review, Vol. 15, No. 2, pp. 29-57.

Libby, R. 1993. Research in Accounting and Auditing, edited by R.H. Ashton and A.H. Ashton, forthcoming. Cambridge, MA: Cambridge University Press.

Libby, T., Salterio, S. E. and Webb, A. 2004. The Balanced Scorecard: The Effects of
Assurance and Process Acountability on Managerial Judgement. The Accounting Review, Vol. 79, No. 4, pp. 1075-1094.

Lipe, M. G. and Salterio, S. E. 2000. The Balanced Scorecard: Judgmental Effect of Common and Unique Performance Measures. The Accounting Review, Vol. 75, No. 3, pp. 283-298.

Nahartyo, Ertambang. 2013. Design and Implementation of Experimental Research, $2^{\text {nd }}$ Edition. Yogyakarta: UPP STIM YKPN.

Nasution, D. and Supriyadi. 2007. Influence of Evidence Sequence, Cognitive Style and Personality to the Belief Revision, Article, $10^{\text {th }}$ National Accounting Symposium, Makassar, July 26-28.

Royal, Carol, et al. 2013. "Knowledge Acquisition Competencies for Non-profit". June 2013. www.cassknowledge.com accessed on April 2015.

Sopanah, 2003. Public Participation and Public Policies of the House of Representative's Knowledge on Local Finance Supervision, Thesis, Master's Program, Gadjah Mada University, Yogyakarta.

Werimon, S. 2007, Public Participation and Public Policy Transparency Correlation Between Members of the House of Representative's Knowledge on Budget and Local Finance Supervision, Article, $10^{\text {th }}$ National Accounting Symposium, Makassar, July 2628.

Winarna, J. and Murni, 2007, Effect of Personal Background, Political Background and Members of the House Representative's Knowledge on Regional Financial Supervision, $10^{\text {th }}$ National Accounting Symposium, Makassar, July 26-28.

Yudono, B. 2002. Optimizing the Role of the Local House of Representatives in the Local Government's Implementation, www.bangda.depdagri.go.id/jurnal/jendela/j endela3.htm. Accessed on November 2011

\section{ENDNOTE}

1 One contrary finding is that of Murni and Witono (2004), who found that gender, age, education, political experience, experience in the House of Representatives, the ideology of their political party and the commission they belonged to did not significantly affect the role of the members of the local House of Representatives in local financial control. 